\title{
THE INTEGRATION OF THE STATE AND CIVIL SOCIETY TO PREVENT YOUTH EXTREMISM IN THE CONTEXT OF LEGAL SOCIALIZATION ${ }^{1}$
}

\author{
Natalia A. Solovyova \\ Volgograd State University, Volgograd, Russian Federation \\ Pavel P. Fantrov \\ Volgograd State University, Volgograd, Russian Federation
}

\begin{abstract}
Introduction: the involvement of the citizens' associations in solving the problems of preventing extremism among young people should become an important trend in the development of partnership relations between the state and civil society. In the context of the problematics, the issues related to increasing the level of legal socialization of Russian youth are of no small importance. The purpose of the study: to characterize the activities of the state and citizens' associations to prevent extremism among young people in the context of legal socialization. The research objectives: to assess the joint activities of the state and civil institutions engaged in the prevention of extremism among young people in the context of legal socialization; to identify the problems of legal socialization of Russian youth and suggest the ways to solve them; to justify the productivity of network crowdsourcing technologies in the joint activities of the state and civil society in the context of prevention of youth extremism. The methodological framework for this research is represented by a system of methods of scientific knowledge, which should include: general scientific, systemic, institutional and sociological methods. Results: in order to combat the manifestations of extremism among young people and successfully socialize young citizens, a complex systematic work of the state and civil society is necessary, which objectively requires the implementation of certain technologies, such as network crowdsourcing. In the paper, when determining the efficiency of this technology, the projects "Cyberdruzhina", "MediaGuard" and "STOPTERROR" were evaluated. Conclusions: it is revealed that the network crowdsourcing technologies act as an optimal mechanism for supporting the system of prevention of youth extremism. Their widespread introduction into the Russian social space can "socialize" the system of preventing extremism among young people, provided that its most important subjects are not only the state structures, but also the constructive associations of citizens.
\end{abstract}

Key words: prevention of extremism, youth, legal socialization, state, civil society, law enforcement agencies, crowdsourcing.

Citation. Solovyova N.A., Fantrov P.P. The Integration of the State and Civil Society to Prevent Youth Extremism in the Context of Legal Socialization. Legal Concept, 2020, vol. 19, no. 2, pp. 21-26. (in Russian). DOI:

\section{ИНТЕГРАЦИЯ ГОСУДАРСТВА И ГРАЖДАНСКОГО ОБЩЕСТВА В СФЕРЕ ПРОФИЛАКТИКИ МОЛОДЕЖНОГО ЭКСТРЕМИЗМА В КОНТЕКСТЕ ПРАВОВОЙ СОЦИАЛИЗАЦИИ ${ }^{1}$}

\author{
Наталья Алексеевна Соловьева \\ Волгоградский государственный университет, г. Волгоград, Российская Федерация
}




\title{
Павел Петрович Фантров
}

\author{
Волгоградский государственный университет, г. Волгоград, Российская Федерация
}

Введение: привлечение ассоциаций граждан к решению проблем профилактики экстремизма в молодежной среде должно стать важным трендом в развитии партнерских отношений государства и гражданского общества. В контексте данной проблематики немаловажное значение имеют вопросы, связанные с повышением уровня правовой социализации российской молодежи. Цель исследования: охарактеризовать деятельность государства и ассоциаций граждан по профилактике экстремизма в молодежной среде в контексте правовой социализации. Задачи исследования: дать оценку совместной деятельности государственных и гражданских институтов, занимающихся профилактикой экстремизма в молодежной среде в контексте правовой социализации; выявить проблемы правовой социализации российской молодежи и предложить пути их решения; обосновать продуктивность сетевых краудсорсинговых технологий при совместной деятельности государства и гражданского общества в контексте профилактики молодежного экстремизма. Методологическая основа данного исследования представлена системой методов научного познания, к которым следует отнести: общенаучные, социологические, системный и институциональный. Результаты: для борьбы с проявлениями экстремизма в молодежной среде и успешной правовой социализации молодых граждан необходима сложная системная работа государства и гражданского общества, что объективно требует реализации ими определенных технологий, например, сетевого краудсорсинга. В статье при определении результативности данной технологии была дана оценка проектам «Кибердружина», «МедиаГвардия» и «STOPTERROR». Выводы: выявлено, что сетевые краудсорсинговые технологии выступают в качестве оптимального механизма по поддержке системы профилактики молодежного экстремизма. Их широкое внедрение в российское социальное пространство способно «социализировать» систему профилактики экстремизма в молодежной среде при условии, что в качестве ее важнейших субъектов выступают не только государственные структуры, но и конструктивно настроенные ассоциации граждан.

Ключевые слова: профилактика экстремизма, молодежь, правовая социализация, государство, гражданское общество, правоохранительные органы, краудсорсинг.

Цитирование. Соловьева Н. А., Фантров П. П. Интеграция государства и гражданского общества в сфере профилактики молодежного экстремизма в контексте правовой социализации // Legal Concept = Правовая парадигма. -2020. - Т. 19, № 2. - C. 21-26. -DOI: https://doi.org/10.15688/lc.jvolsu.2020.2.3

\section{Введение}

Благодаря своим возрастным и социокультурным особенностям молодые люди объективно являются необходимым общественным ресурсом модернизационных изменений в российском социуме. Они стремятся к новому и неизведанному, и им зачастую тесно в жестких рамках социальных условностей и ограничений, что нередко приводит к вовлечению их в экстремистскую деятельность. В российском обществе имеется целый ряд неблагоприятных общественных факторов, склоняющих молодых людей к осуществлению экстремистской деятельности, к которым прежде всего следует отнести: чрезмерную поляризацию высших и низших социальных групп; когнитивный диссонанс; социально-экономические проблемы, детерминирующие снижение востребованности креативного потенциала молодежи; идеологический прессинг со стороны радикальных общественных организаций.
Таким образом, необходимо создавать в российском обществе условия и искать новые механизмы профилактики экстремизма в молодежной среде - переходить от уровня работы отдельных образовательных учреждений к государственной межведомственной политике с активным привлечением общественных организаций к деятельности по профилактике экстремистского поведения. Актуальность проблемы в контексте научного дискурса определяется:

1) возросшими рисками, вызванными развитием целого ряда негативных явлений (экстремизма, религиозного радикализма, правового нигилизма, ксенофобии и т. д.) в общественной жизни молодежи;

2) объективной необходимостью выработки научных рекомендаций по интеграции и повышению эффективности профилактики молодежного экстремизма в контексте совместной деятельности государства и гражданского общества. 


\section{Оценка деятельности государственных}

и гражданских институтов

по профилактике

молодежного экстремизма

\section{в контексте правовой социализации}

В условиях снижения уровня доверия молодежи к органам власти активное противодействие групп граждан властным новациям зачастую выводит существующие конфликтные ситуации на уровень повышенной социальной напряженности. В результате адаптации молодого поколения к социальнонапряженным условиям сложнее выполняется процесс ее успешной правовой социализации. Инкорпорация и укоренение нигилистических паттернов поведения в сознании молодежи, усиленных националистическими или эрзац-религиозными конструктами, способствует выработке и реализации системы действий или поступков, которые грубо нарушают принципы мирного сосуществования индивидов, создают угрозу для жизни и здоровья граждан, способствуют нагнетанию общественно-политической напряженности в российском социуме. Такое положение дел порождает «группу риска» молодежи, склонную к проявлениям экстремизма, что является актуальной проблемой, выходящей за рамки правоохранительной деятельности.

Высокий уровень правовой социализации молодых граждан является необходимым условием развития правового государства и гражданского общества [6, с. 64]. Следует согласиться с мнением В.Н. Гуляихина, что повышение уровня правовой социализации молодежи в результате продуктивного взаимодействия государства и гражданского общества поможет значительно уменьшить число преступлений экстремистской направленности [1, с. 107], которые зачастую совершаются молодыми людьми по причине неосведомленности о том, что в законе имеется норма, которая запрещает такое поведение.

Интеграция деятельности государства и гражданского общества по профилактике экстремизма в молодежной среде в контексте правовой социализации предполагает решение следующих задач: ресурсно-технологическое обеспечение совместной деятельности правоохранительных органов и ассоциаций граждан; реализация объединенных усилий, способных повысить социальную активность граждан; координирование целей коллективных действий, разработка мероприятий по защите интересов молодежи; согласование приоритетов и консолидация сторон; прозрачность функционирования государственных и негосударственных акторов профилактики молодежного экстремизма через создание единого информационного поля с применением сетевых технологий. Для решения этих задач в современной России развивается система горизонтальных общественных связей, которая поддерживается такими общественно-политическими структурами, как НКО или НПО [5, с. 6].

Использование сетевых технологий при совместной деятельности государства и гражданского общества по профилактике молодежного экстремизма способствует решению следующих задач: реализация права граждан участвовать в управлении делами государства для привлечения внимания россиян к решению данной проблемы; развитие кооперационнокоммуникативных связей органов государственной власти и гражданского общества; совершенствование законодательства по профилактике экстремизма и легитимация нормотворческих идей в данной сфере. Следует отметить, что в современной России не все из этих задач реализуются в полной мере. Кроме того, остается неясным, какие из них власть считает приоритетными. На первый план следует выдвинуть реализацию права граждан участвовать в управлении делами государства, в том числе в вопросах совершенствования законодательства по профилактике экстремизма в молодежной среде. Сегодня молодые граждане сталкиваются с объективными и субъективными препятствиями, в результате нередко у них создается впечатление имитации демократии. Устранение негативных предпосылок возможно при условии готовности власти вести продуктивный диалог с гражданским обществом, учитывая его социально-политические запросы. Сетевые технологии являются как раз тем оптимальным механизмом по профилактике молодежного экстремизма, способным вовлечь значительное количество субъектов в горизонтальные социальные связи посредством «новых медиа» и основанных на них smart-проек- 
тов. Их развитие способствует более четкому выражению позиции граждан по актуальным проблемам обеспечения национальной безопасности, включая борьбу с молодежным экстремизмом. Их успешная адаптация к российскому социальному пространству будет способствовать «социализации» системы профилактики экстремизма в молодежной среде и продвижению во взаимодействии личности и государства к модели общества либерального типа, исключая возможность возникновения ограничений для коммуникативных связей при решении актуальных проблем: как проявления экстремистских настроений в социуме, так и устойчивого развития российского суперэтноса.

В качестве одной из инновационных и эффективных сетевых технологий в области профилактики экстремизма в молодежной среде следует выделить краудсорсинг, означающий передачу определенных функций, которые выполняло ранее государство, конкретному кругу субъектов - представителям гражданского общества. Результативность сетевых краудсорсинговых технологий заключается в решении конструктивно настроенными ассоциациями граждан проблем в области информационной безопасности (выявление и блокировка сайтов экстремистской направленности, распространение информации в сети Интернет по борьбе с противоправным контентом и пр.). В России успешно реализуются краудсорсинговые проекты, нацеленные на профилактику и борьбу с сетевым экстремизмом в молодежной среде («Кибердружина», «МедиаГвардия» и «STOPTERROR»).

Сетевой краудсорсинговый проект «Кибердружина» был создан Лигой безопасного интернета и функционирует в Российской Федерации с 2011 года. Он объединяет свыше 20 тысяч добровольцев в 36 регионах России, однако на федеральном уровне деятельность кибердружинников в настоящее время законодательно не регламентирована, но она может быть узаконена в 2020 г., поскольку законопроект об их функционировании дорабатывается. Его значение заключается в следующем: депутатами от партии «Единая Россия» инициируется создание кибердружины, имеющей статус общественной организации и изъявившей желание противодействовать рас- пространению противоправной информации в сети Интернет с уведомлением соответствующего органа исполнительной власти. В ряды кибердружинников можно вступить добровольно по достижении совершеннолетия. Рассмотрение данного законопроекта и дальнейшее его утверждение может способствовать повышению эффективности профилактики экстремисткой деятельности, осуществляемой при реализации сетевых краудсорсинговых технологий кибердружинниками и правоохранительными органами. Подтверждением этому служит тот факт, что за последние 5 лет с помощью кибердружинников было заблокировано не менее 10 тысяч интернет-ресурсов, а также выявлено свыше сотни преступлений, в том числе и экстремистской направленности [2].

Успешным примером профилактики экстремизма в молодежной среде является реализация Молодой Гвардией Единой России (далее - МГЕР) сетевого краудсорсингового проекта «МедиаГвардия», функционирующего с 13 марта 2013 года. Его цель - интеграция усилий активистов МГЕР и силовых структур для выявления сайтов экстремистской направленности. Так, в 2018 г. силами «молодогвардейцев» проверено более 50000 интернетресурсов, из которых выявлено и заблокировано свыше 5000 интернет-страниц, содержащих противоправный контент, разработаны методические рекомендации «Как не попасть в лапы вербовщиков ИГИЛ», распространенные в сети Интернет и российских образовательных учреждениях [3].

C осени 2015 г. в России реализуется краудсорсинговый проект «STOPTERROR». Он организован с целью мониторинга интернет-пространства, в том числе и социальных сетей, на наличие контента, пропагандирующего экстремизм и межрелигиозную вражду. За первые 2 года его функционирования координаторами проекта было рассмотрено свыше 7000 обращений граждан со ссылками на конкретные ресурсы противоправного контента, более тысячи из которых были заблокированы [4].

Использование краудсорсинговых технологий в общественной практике подразумевает получение относительно быстрого и ожидаемого результата по профилактике экстре- 
мизма в молодежной среде. В современных реалиях необходима выработка алгоритма и критериев использования этих сетевых технологий в деятельности государственных структур и ассоциаций граждан, при этом, не ущемляя интересы последних. В связи с этим для их успешной реализации важно добиться партнерского взаимодействия гражданских ассоциаций и государственных учреждений, ведь профилактика и предотвращение молодежного экстремизма в рамках интересов национальной безопасности России.

\section{Выводы}

Становление молодых людей в качестве субъектов публично-правовой деятельности оказывает значительное влияние на снижение преступлений экстремистской направленности. В значительной степени эффективность профилактики молодежного экстремизма зависит от успешности правовой социализации, которая способна расширить диапазон возможностей самореализации молодого человека, что служит залогом поддержания безопасности личности, общества и государства [7, с. 267]. Тем не менее российской системе обеспечения национальной безопасности присущ ряд недостатков, связанный с проведением мероприятий в рамках правовой социализации российской молодежи, к ним следует отнести: вопервых, стихийный характер, чем нередко пользуются радикальные группировки; во-вторых, «объективированный» характер, когда социализируемые молодые люди выступают в качестве ее пассивных объектов.

Из-за глобальных вызовов российскому социуму и сложностей догоняющей модернизации процесс социализации российской молодежи требует объединения всех здоровых сил общества. Результативность процесса правовой социализации предполагает формирование умения молодого человека ориентироваться в политико-правовой системе, а также правомерно отстаивать интересы. В связи с этим целесообразно совершенствование модели профилактики экстремизма в молодежной среде, которая должна предполагать не только иерархические (вертикальные) связи между ее субъектами, как происходит в настоящее время, но и горизонтальные коммуникации.
Иными словами, следует «социализировать» систему профилактики экстремизма в молодежной среде, развивая партнерские отношения между государством и гражданским обществом. Без целенаправленной деятельности всех акторов на скоординированной основе профилактика молодежного экстремизма не будет достаточно эффективной. Для их продуктивного взаимодействия в контексте рассматриваемой проблематики необходимо достижение ряда условий: наличие мощной ресурсно-технологической базы функционирования институтов гражданского общества и механизмов, обеспечивающих их «вхождение» в систему национальной безопасности; согласование приоритетов и консолидация сторон на основе патриотических ценностей; повышение уровня правосознания и правовой культуры молодого поколения; широкое внедрение сетевых краудсорсинговых технологий.

\section{ПРИМЕЧАНИЕ}

${ }^{1}$ Статья подготовлена при финансовой поддержке гранта РФФИ № 20-011-00688 (А) «Модель профилактики экстремизма в молодежной среде: интеграция деятельности гражданских ассоциаций и силовых структур в контексте правовой социализации».

The reported study was funded by RFBR, project no. 20-011-00688 (A) "Model for the prevention of extremism among the youth: integration of the activities of civic associations and law enforcement agencies in the context of legal socialization".

\section{СПИСОК ЛИТЕРАТУРЫ}

1. Гуляихин, В. Н. Архетипический базис правового воспитания личности / В. Н. Гуляихин, Е. В. Пантелеев // Философия права. - 2017. - № 1.C. $105-112$.

2. Кибердружина. - Электрон. текстовые дан. Режим доступа: https://kiberdruzhina.ru (дата обращения: 27.02.2020). - Загл. с экрана.

3. МедиаГвардия. - Электрон. текстовые дан. Режим доступа: https://everything.kz/article/47135422mediagvardiya-v-2018-godu-nashi-itogi (дата обращения: 27.02.2020). - Загл. с экрана.

4. Проект STOPTERROR: промежуточные итоги. - Электрон. текстовые дан. - Режим доступа: https://www.oprf.ru/press/news/2017/newsitem/ 40861 (дата обращения: 27.02.2020). - Загл. с экрана. 
5. Рудковский, В. А. Современная доктрина гражданского общества: некоторые особенности / В. А. Рудковский // Научный вестник Волгоградского филиала РАНХиГС. Серия: Юриспруденция. 2015. - № 2. - С. 4-8.

6. Рудковский, В. А. Чувство ответственности и объективность правопорядка / В. А. Рудковский // Вектор науки Тольяттинского государственного университета. Серия: Юридические науки. 2016. - № 2. - С. 63-67.

7. Фантров, П. П. Национальная модель политической социализации молодежи и национальная безопасность России / П. П. Фантров // Национальные интересы: приоритеты и безопасность. -2017. - № 2. - С. 261-269.

\section{REFERENCES}

1. Gulyaikhin V.N., Panteleev E.V. Arhetipicheskiy bazis pravovogo vospitaniya lichnosti [Archetypal Basis of Legal Education of an Individual]. Filosofiya prava [Philosophy of Law], 2017, no. 1, pp. 105-112.

2. Kiberdruzhina [Cybertwin]. URL: https: //kiberdruzhina.ru (accessed 27 February 2020).
3. MediaGvardiya [Media Guard]. URL: http:// vsrf.ru/stor_pdf.php?id=1754708 (accessed 27 February 2020).

4. Proekt STOPTERROR: promezhutochnye itogi [STOPTERROR Project: Subtotals]. URL: https:// www.oprf.ru/press/news/2017/newsitem/40861 (accessed 27 February 2020).

5. Rudkovsky V.A. Sovremennaya doktrina grazhdanskogo obshchestva: nekotorye osobennosti [The Modern Doctrine of Civil Society: Some Features]. Nauchnyj vestnik Volgogradskogo filiala RANHiGS. Seriya: Yurisprudenciya [Scientific Bulletin of Volgograd Branch ofRANEPA. Series: Law], 2015, no. 2, pp. 4-8.

6. Rudkovsky V.A. Chuvstvo otvetstvennosti i obyektivnost pravoporyadka [A Sense of Responsibility and the Objectivity of the Rule of Law]. Vektor nauki Tolyattinskogo gosudarstvennogo universiteta. Seriya: Yuridicheskie nauki [Vector Science of Togliatti State University. Series: Law], 2016, no. 2, pp. 63-67.

7. Fantrov P.P. Natsionalnaya model politicheskoy sotsializatsii molodezhi i natsionalnaya bezopasnost Rossii [National Model of Political Socialization of Youth and National Security of Russia]. Nacionalnye interesy: prioritety $i$ bezopasnost [National Interests: Priorities and Security], 2017, no. 2, pp. 261-269.

\section{Information About the Authors}

Natalia A. Solovyova, Candidate of Sciences (Jurisprudence), Associate Professor, Head of the Department of Criminal Procedure and Criminalistics, Volgograd State University, Prosp. Universitetsky, 100, 400062 Volgograd, Russian Federation, solovieva_na@volsu.ru, https://orcid.org/0000-0002-9698-0845

Pavel P. Fantrov, Candidate of Sciences (Politics), Specialist in Educational and Methodical Work, Department of Criminal Procedure and Criminalistics, Volgograd State University, Prosp. Universitetsky, 100, 400062 Volgograd, RussianFederation, pavelfantrov@volsu.ru, https://orcid.org/0000-0002-9832-6169

\section{Информация об авторах}

Наталья Алексеевна Соловьева, кандидат юридических наук, доцент, заведующая кафедрой уголовного процесса и криминалистики, Волгоградский государственный университет, просп. Университетский, 100, 400062 г. Волгоград, Российская Федерация, solovieva_na@volsu.ru, https://orcid.org/0000-0002-9698-0845

Павел Петрович Фантров, кандидат политических наук, специалист по учебно-методической работе кафедры уголовного процесса и криминалистики, Волгоградский государственный университет, просп. Университетский, 100, 400062 г. Волгоград, Российская Федерация, pavelfantrov@volsu.ru, https://orcid.org/0000-0002-9832-6169 